UCRL-ID-135215

\title{
Demonstration of Lithographic Patterning in Measurements of General and Localized Corrosion on Alloy 22
}

Peter J. Bedrossian

Joseph C. Farmer

July 1999

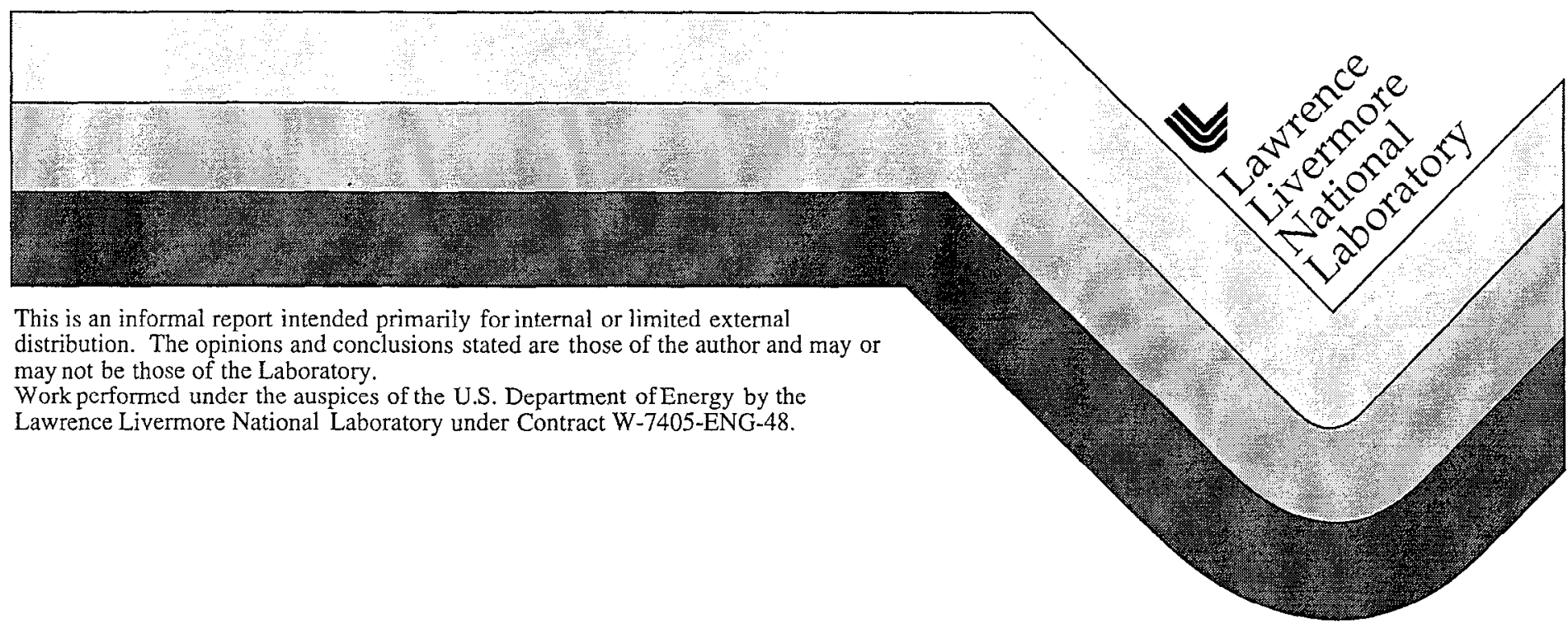




\section{DISCLAIMER}

This document was prepared as an account of work sponsored by an agency of the United States Government. Neither the United States Government nor the University of California nor any of their employees, makes any warranty, express or implied, or assumes any legal liability or responsibility for the accuracy, completeness, or usefulness of any information, apparatus, product, or process disclosed, or represents that its use would not infringe privately owned rights. Reference herein to any specific commercial product, process, or service by trade name, trademark, manufacturer, or otherwise, does not necessarily constitute or imply its endorsement, recommendation, or favoring by the United States Government or the University of California. The views and opinions of authors expressed herein do not necessarily state or reflect those of the United States Government or the University of California, and shall not be used for advertising or product endorsement purposes.

This report has been reproduced directly from the best available copy.

Available to DOE and DOE contractors from the Office of Scientific and Technical Information

P.O. Box 62, Oak Ridge, TN 37831

Prices available from (615) 576-8401, FTS 626-8401

Available to the public from the

National Technical Information Service

U.S. Department of Commerce

5285 Port Royal Rd.,

Springfield, VA 22161 


\title{
Demonstration of Lithographic Patterning in Measurements of General and Localized Corrosion on Alloy 22
}

\author{
Peter J. Bedrossian and Joseph C. Farmer \\ Department of Chemistry and Materials Science \\ Lawrence Livermore National Laboratory, Livermore CA 94550
}

\begin{abstract}
We have demonstrated a new technique capable of detecting generalized corrosion of metallographically-polished materials with nanometer-scale precision. After exposing a lithographically-patterned coupon of Alloy 22 to an electrolyte in a potentiostaticallycontrolled cell for twenty-four hours, we detected the loss of up to $130 \mathrm{~nm}$ of metal In addition, "wormholes" were detected at certain points of intersection of three grain boundaries.
\end{abstract}

\section{Introduction}

The emphasis on the use of Corrosion-Resistant Materials (CRM's) in the Engincered Barrier Systems (EBS) for the proposed Geological Repository has stimulated the exploration of novel techniques for detecting corosion in trace amounts which may be undetectable by traditional methods such as weight loss. The Atomic Force Microscope (AFM), with its atomic-level sensitivity to surface topography, enables the detection of nanometer-scale changes in surface topography introduced by corrosion. The detection of the effects of aqueous corrosion on such a fine scale is made necessary by the need to predict over a geological time scale the performance of materials which typically do not corrode macroscopically over the time scale of laboratory tests in relevant environments.

The procedure used here is illustrated in Figure 1. A test coupon is first polished metallographically to a mirror finish with a total rms roughness below $2 \mathrm{~nm}$, as measured with an AFM. Next, it is patterned with a series of photoresist lines. The masked sample is then exposed to an electrolyte in a potentiostatically-controlled cell for some fixed time. Once the sample is removed, the mask is dissolved away with acetone. After the removal of corrosion products and mineral deposits, what remains is a grating in which lines of protected base metal alternate with lines of exposed material. If the corrosion resulted in the dissolution of metal, then the lines of exposed material will be depressed. The amount of material lost can then be measured directly with an AFM.

The experiments described below are covered under the YMP Approved Activity Plan AP-E20-70. Sample preparation procedures are covered under the YMP Approved TIP APE20-71. Sample numbers refer to YMP controlled coupon designations. Image numbers are identical to the controlled file names. 
Base Metal

1) Pattern Lines Lithographically

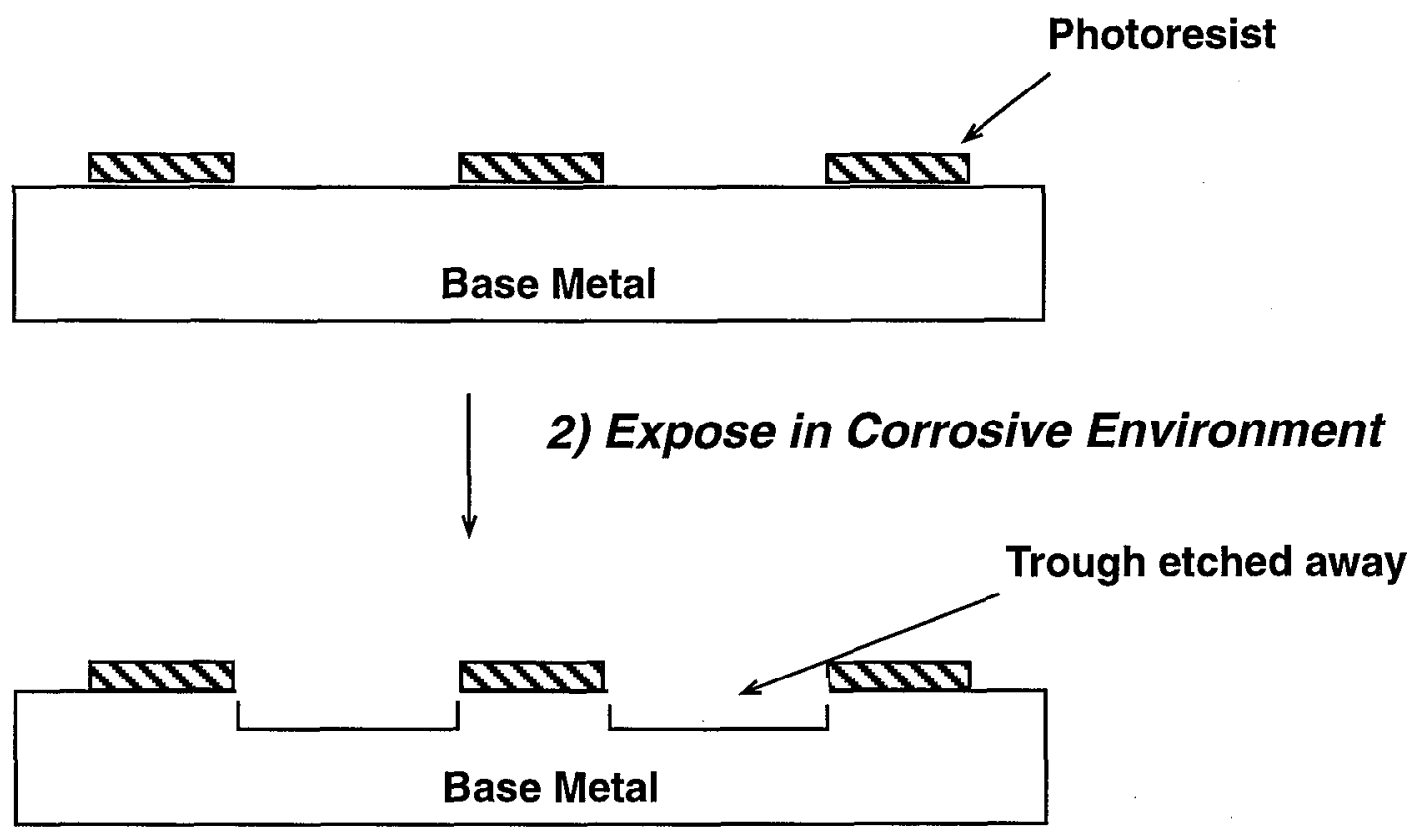

3) Wash away Photoresist

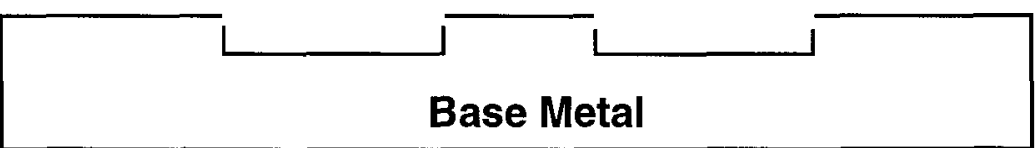

Figure 1: Method for AFM-based detection of metal dissolution by corrosion. 


\section{Method}

Alloy 22 Test Coupon DEA325 was lithographically patterned with a photoresist mask and then exposed to Simulated Concentrated Well Water (SCW) at $90^{\circ} \mathrm{C}$ for 24 hours, at $+200 \mathrm{mV}$ with respect to $\mathrm{Ag} / \mathrm{AgCl}$ reference electrode. Following the polarization, the mask was removed by repeated heating and ultrasonic agitation of the sample in Acetone. A scale buildup was removed by ultrasonic agitation in deionized water.

\section{Observations}

The observations are illustrated in the accoupanying figures:

\section{A) General Corrosion}

Sample DEA325: Edge of Trough Pattern The troughs are formed from corrosion in the electrolyte. The base metal protected by the photoresist during polarization is undisturbed.5

Sample DEA325: Grating left after corrosion has etched troughs. The trough depths are on

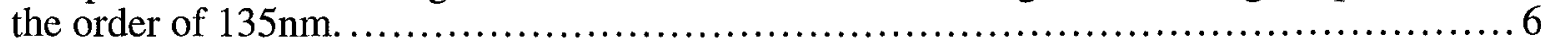

Line Profile Through Image DEA325.f11, showing the depths of the etched troughs......7

\section{B) Local Corrosion}

Localized attack was observed only at specific triple junctions, with the grain boundaries identified by optical microscopy.

DEA325: Localized Attack at a Triple Junction....................................8

Line Cut Through the Site of Attack in Image DEA325.p22, showing a depth of 270nm.. .9

DEA325: Localized Attack at Another Triple Junction ........................... 10

DEA325: Localized Attack at Yet Another Triple Junction........................ 11

\section{Discussion}

An AFM-based measurement shows easily and unambiguously the quantity of material dissolved under the polarization conditions described above. We believe that it is a viable method for measuring general corrosion rates for short-term laboratory tests on CorrosionResistant Materials.

Evidence of localized corrosion was sparse. Some localized attack was observed, and because the grain boundaries of the corroded material appeared clearly in optical micrographs, the sites of localized attack which we detcctcd could be identified as triple junctions. We emphasize that most triple junctions are not attacked, and at this time we are unable to correlate the presence or absence of triplc junction attack with the specific misorientations of the associated grain boundaries. Perhaps Orientation Imaging Microscopy (OIM) cold shed light on this issue in the future.

We note that a loss of $100 \mathrm{~nm}$ of $\mathrm{C} 22$ on a conventional $5 / 8$ "-diameter weight loss coupon held in a holder with a gasket ID of $11 \mathrm{~mm}$ uncompressed and $10 \mathrm{~mm}$ compressed would represent a volume loss of $7.8 \times 10^{-6} \mathrm{~cm}^{3}$. Using the specific gravity of 8.69 in the 
Haynes data sheet for its Hastelloy C-22, the total weight loss would be $67 \mu \mathrm{g}$. If the corrosion rate were, hypothetically, linear, then the total weight loss after one hour would be only $5.5 \mu \mathrm{g}$.

Finally, we emphasize that the one measurement presented here should not be extrapolated to a corrosion rate, because at this time we have no basis for extracting a general corrosion rate from only one data point. Many more data points will be required before we can do that.

\section{Acknowledgments}

The authors are grateful to R. Kershaw for sample polishing, to D. Ciarlo for lithographic patterning, to J. Estill, K, King, S. Gordon, and L. Logoteta for electrochemical testing, and to D. Fix for assistance with AFM measurements. This work was performed at Lawrence Livermore National Laboratory under the auspices of the US Dept. of Energy under Contract W-7405-Eng-48 and was supported by the Yucca Mountain Program. 


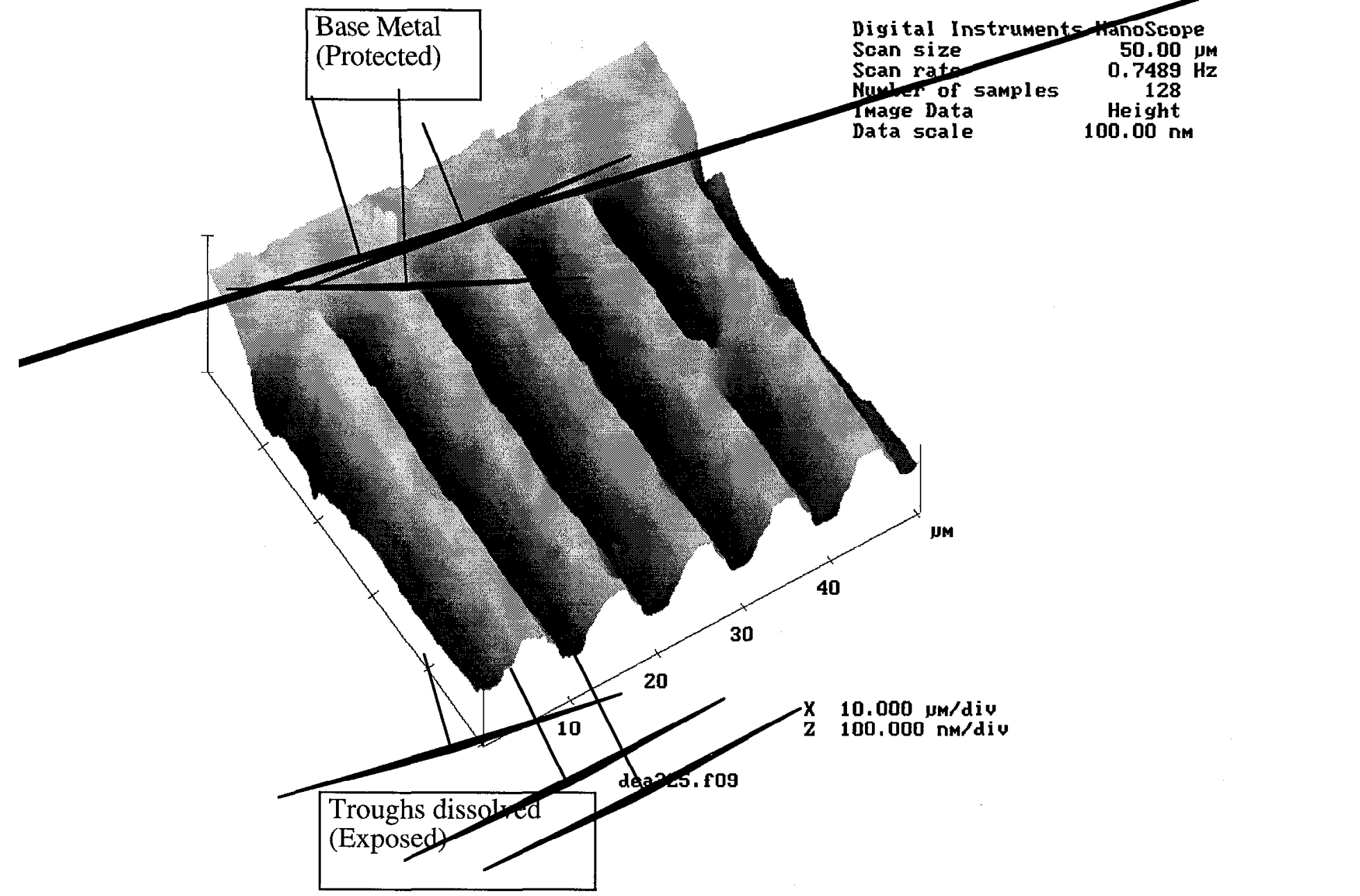

Sample DEA325: Edge of Trough Pattern The troughs are formed from corrosion in the electrolyte. The base metal protected by the photoresist during polarization is undisturbed. 


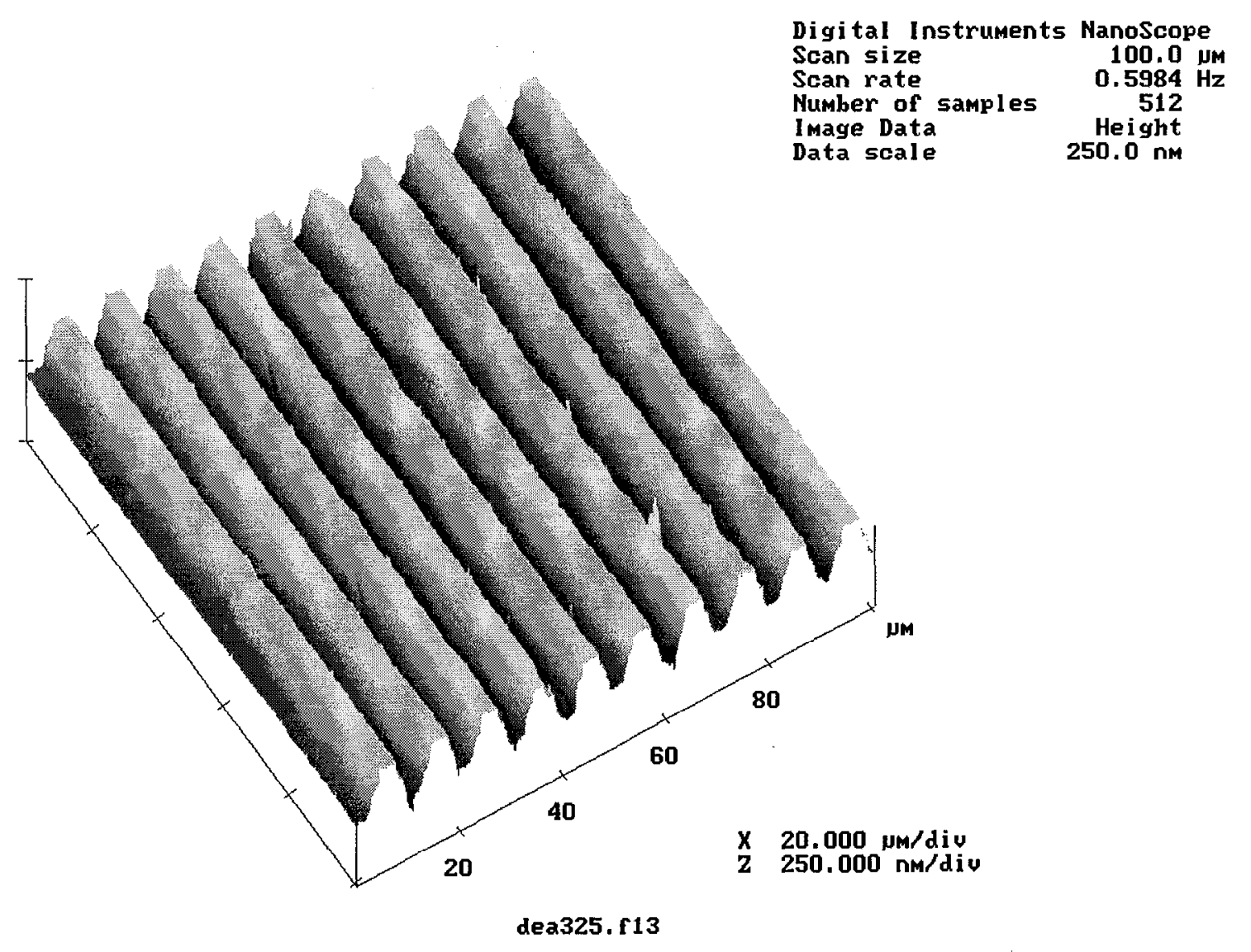

Sample DEA325: Grating left after corrosion has etched troughs. The trough depths are on the order of $135 \mathrm{~nm}$. 


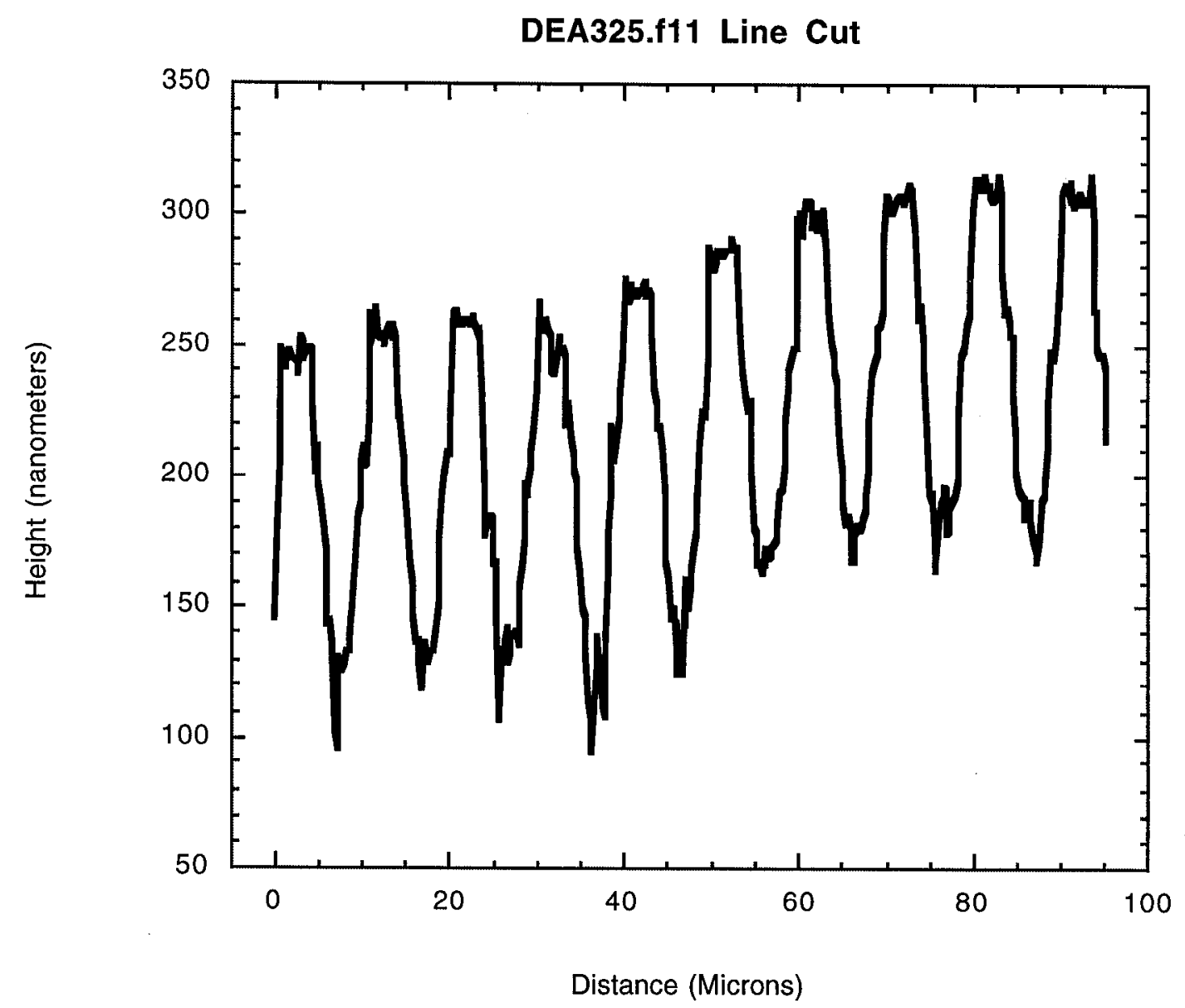

Line Profile Through Image DEA325.f11, showing the depths of the etched troughs. 


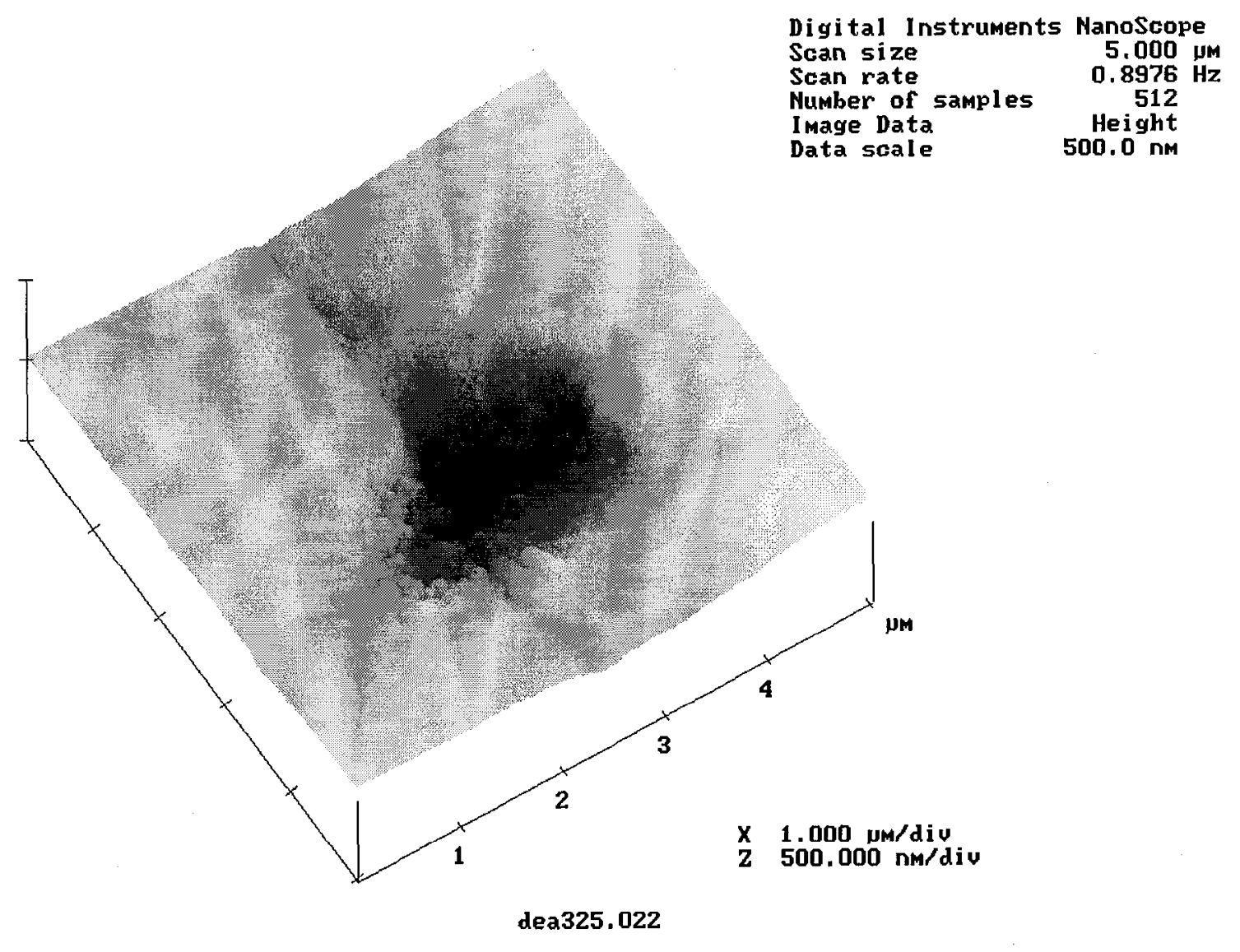

DEA325: Localized Attack at a Triple Junction 


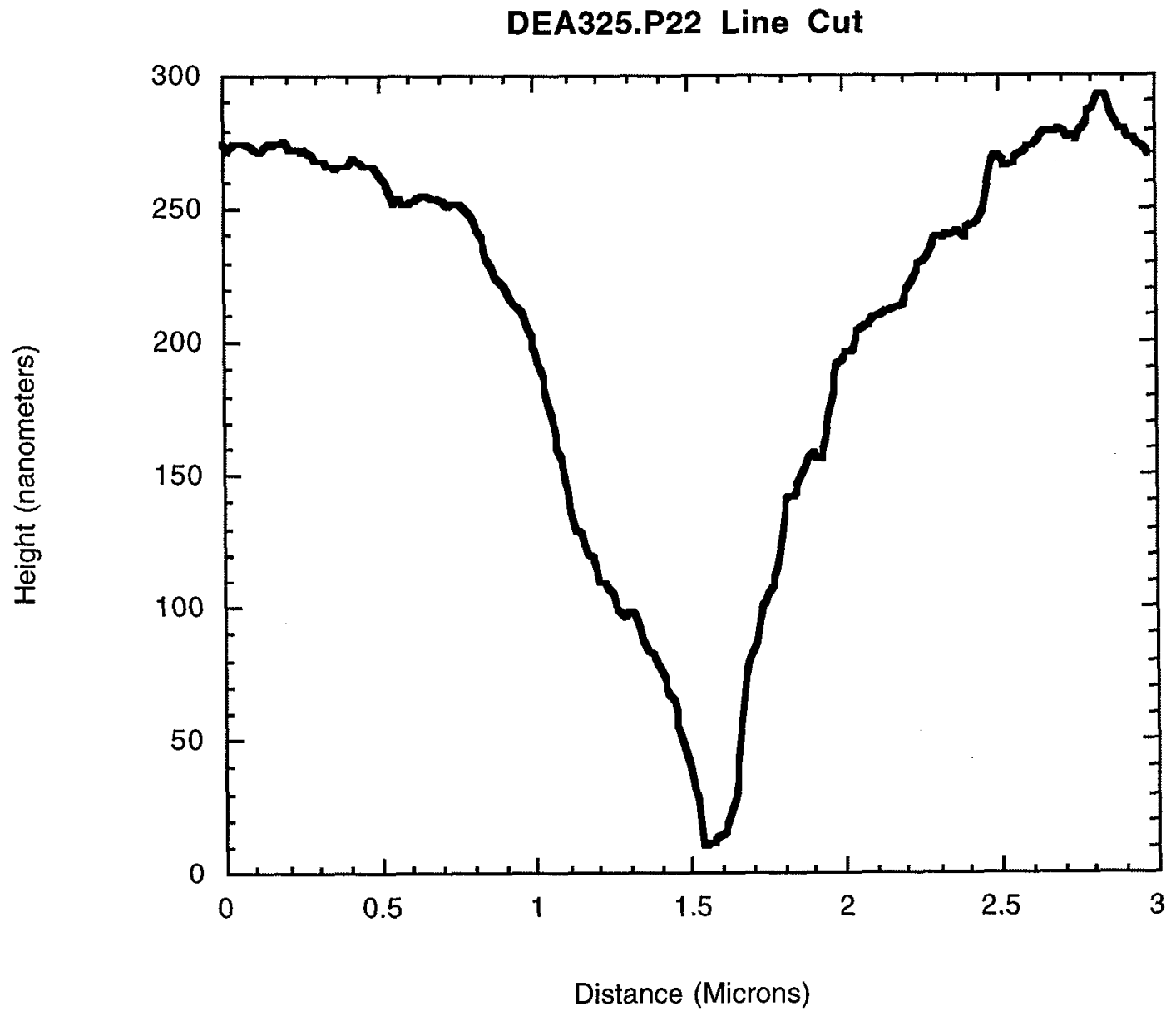

Line Cut Through the Site of Attack in Image DEA325.p22, showing a depth of $270 \mathrm{~nm}$. 


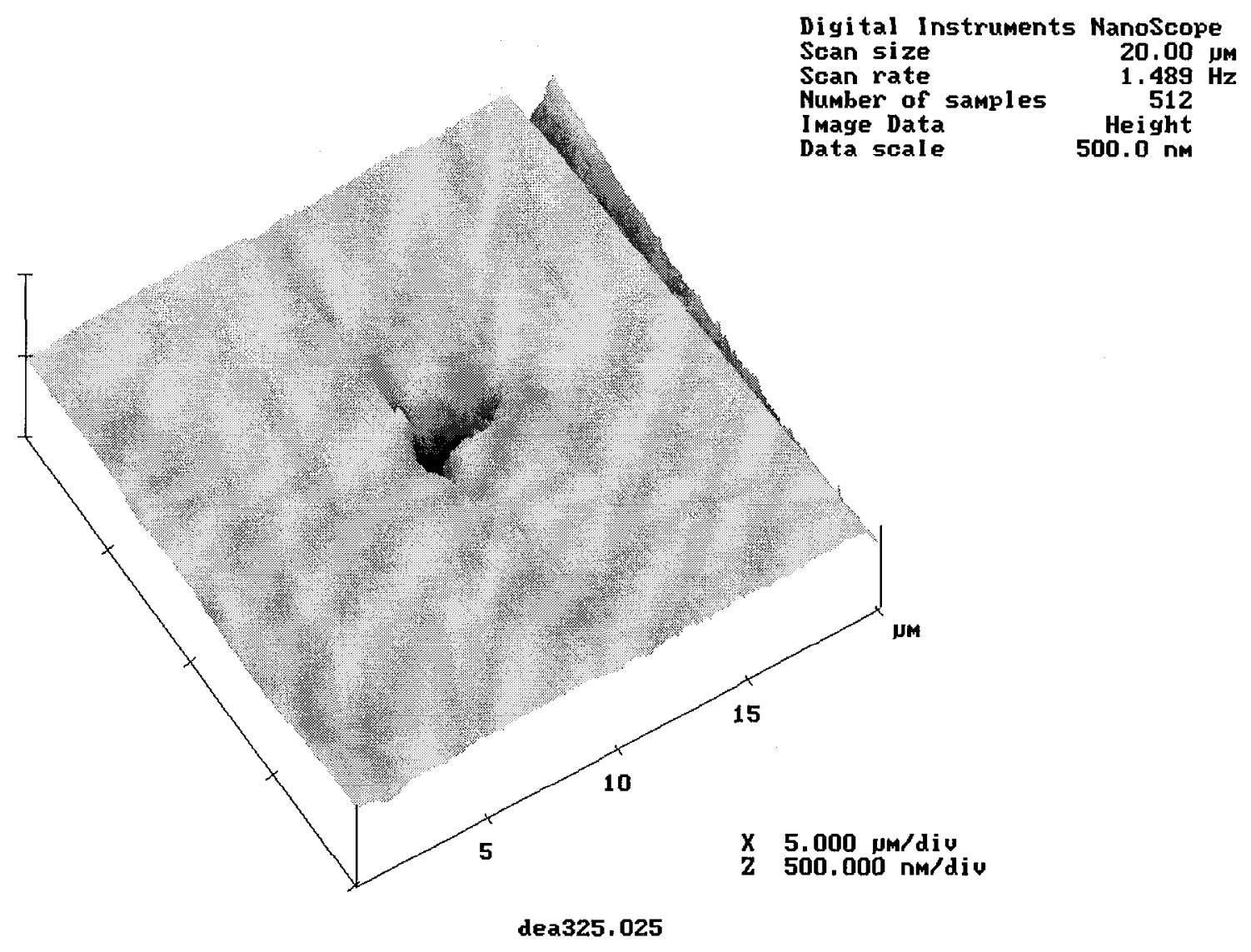

DEA325: Localized Attack at Another Triple Junction 


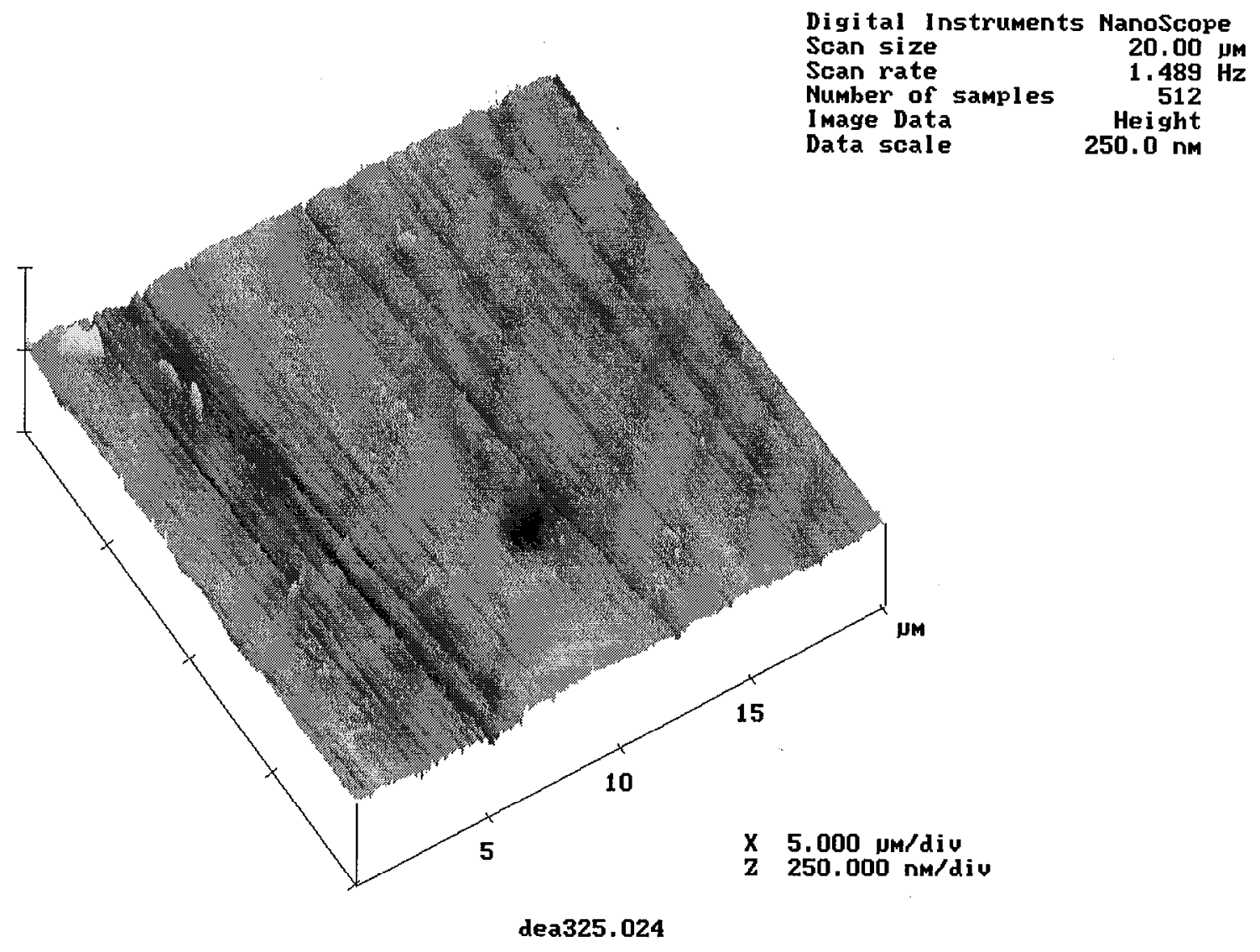

DEA325: Localized Attack at Yet Another Triple Junction 